\title{
Identification and Characterization of Plasmodiophora brassicae Primary Infection Effector Candidates that Suppress or Induce Cell Death in Host and Nonhost Plants
}

\author{
Wang Chen, ${ }^{1}$ Yan Li, ${ }^{1}$ Ruibin Yan, ${ }^{1}$ Li Xu,${ }^{1}$ Li Ren, ${ }^{1}$ Fan Liu, ${ }^{1}$ Lingyi Zeng, ${ }^{1}$ Huan Yang, ${ }^{1}$ Peng Chi, ${ }^{1}$ Xiuzhen Wang, ${ }^{1}$ \\ Kunrong Chen, ${ }^{1}$ Dongfang $\mathrm{Ma},{ }^{2}$ and Xiaoping Fang1,† \\ ${ }^{1}$ Oil Crops Research Institute of Chinese Academy of Agricultural Sciences, Key Laboratory of Biology and Genetics Improvement of Oil \\ Crops, Ministry of Agriculture and Rural Affairs, Wuhan 430062, Hubei, China \\ ${ }^{2}$ Hubei Collaborative Innovation Center for Grain Industry, Yangtze University, Jingzhou 434025, China \\ Accepted for publication 8 June 2019.
}

\begin{abstract}
Clubroot caused by Plasmodiophora brassicaeis one of the most important diseases in cruciferous crops. The recognition of $P$. brassicae by host plants is thought to occur at the primary infection stage, but the underlying mechanism remains unclear. Secretory proteins as effector candidates play critical roles in the recognition of pathogens and the interactions between pathogens and hosts. In this study, 33 P. brassicae secretory proteins expressed during primary infection were identified through transcriptome, secretory protein prediction, and yeast signal sequence trap analyses. Furthermore, the proteins that could suppress or induce cell death were screened through an Agrobacterium-mediated plant virus transient expression system and a protoplast transient
\end{abstract}

ABSTRAC expression system. Two secretory proteins, PBCN_002550 and PBCN_005499, were found to be capable of inducing cell death associated with $\mathrm{H}_{2} \mathrm{O}_{2}$ accumulation and electrolyte leakage in Nicotiana benthamiana. Moreover, PBCN_002550 could also induce cell death in Chinese cabbage. In addition, 24 of the remaining 31 tested secretory proteins could suppress mouse Bcl-2-associated X protein-induced cell death, and 28 proteins could suppress $\mathrm{PBCN}_{-}$ 002550-induced cell death.

Keywords: plant immunity, Plasmodiophora brassicae, primary infection, secretory proteins
Clubroot is one of the most important diseases in cruciferous crops, including Chinese cabbage, oilseed rape, and radish, and it has been observed in $>60$ countries worldwide (Dixon 2009). In China, clubroot disease has been found in most provinces and affects $\sim 4$ million ha per year (Chai et al. 2014). Clubroot disease is caused by Plasmodiophora brassicae, which is a soilborne obligate protist that belongs to the genus Plasmodiophora in Rhizaria. Rhizaria shares a common ancestor with Stramenopiles and Alveolata (Schwelm et al. 2016, 2018; Sierra et al. 2016). The disease cycle of $P$. brassicae in plants consists of two phages: primary infection, which mainly occurs in root hairs, and secondary infection, which occurs in tissues adjacent to the root cortex (Kageyama and Asano 2009). Primary infection can occur in both host and nonhost plants, but secondary infection can occur only in host plants (Feng et al. 2012). The recognition of $P$. brassicae by host plants is thought to occur during primary infection (McDonald et al. 2014), but the mechanism underlying the recognition of $P$. brassicae, the interactions between $P$. brassicae and plants, and the mechanism through which $P$. brassicae overcomes plant immunity to achieve successful infection are not well understood.

†Corresponding author: X. Fang; xpfang2008@163.com

Funding: This work was supported by National Key Research and Development Program of China grant 2018YFD0200900 and Natural Science Foundation of Hubei Province grant 2018CFB255.

W. Chen and Y. Li contributed equally to this work.

*The $\boldsymbol{e}$-Xtra logo stands for "electronic extra" and indicates that two supplementary figures and two supplementary tables are published online.

The author(s) declare no conflict of interest.

(C) 2019 The American Phytopathological Society
The plant immune system has two branches (Jones and Dangl 2006). One is referred to as pathogen-associated molecular pattern or microbe-associated molecular pattern-triggered immunity (PTI), which can halt further colonization by both pathogens and nonpathogens. However, successful pathogens can deploy effectors to interfere with PTI, which results in effector-triggered susceptibility. The second branch of the plant immune system utilizes nucleotide-binding site leucine-rich repeat (NB-LRR) proteins to recognize pathogen effectors and consequently, activate plant immunity. This branch is referred to as effector-triggered immunity.

From the perspective of pathogens, effectors are critical for successful infection. Specifically, effectors secreted by pathogens are important molecules that can modulate plant defenses and enhance microbial fitness (Hogenhout et al. 2009). Secretory proteins as effector candidates have been widely studied in fungi, oomycetes, bacteria, and nematodes (Block et al. 2014; Erickson et al. 2018; Li et al. 2017; Lyu et al. 2016; Ma et al. 2017; Nguyen et al. 2018; Zheng et al. 2018). Many secretory proteins play a role as pathogen-associated molecular patterns or microbe-associated molecular patterns that can elicit plant immunity (Chen et al. 2013; Kamoun et al. 1998; Wei et al. 1992; Yang et al. 2018). Many other secretory proteins have been reported to suppress plant immunity (King et al. 2014; Lin et al. 2016; Liu et al. 2016).

Five hundred fifty-three of the 9,730 genes in the P. brassicae isolate e3 genome are predicted to encode secretory proteins (Schwelm et al. 2015). Although clubroot and P. brassicae have been studied for $>140$ years, few studies have investigated the functions of secretory proteins and effectors in the $P$. brassicae infection process and subsequent disease progression (Pérez-López et al. 2018). Studies showed that a methyltransferase secreted by $P$. brassicae can methylate salicylic acid and alter host susceptibility to P. brassicae (Bulman et al. 2019; Ludwig-Müller et al. 2015). However, the identities of the other proteins involved in the $P$. brassicae infection process and subsequent disease progression remain unknown. 
In our research, five transcriptomes of hydroponic oilseed rape during primary infection with $P$. brassicae were sequenced. The $P$. brassicae genes expressed during primary infection were screened by mapping to the $P$. brassicae isolate 3 genome and analyzing the fragments per kilobase per million reads (FPKM) value. Putative secretory protein genes were then predicted using bioinformatics software, and their signal peptide (SP) functions were tested through a yeast trap assay. The capacities of these secretory proteins to induce or suppress cell death were subsequently assessed. The results of these experiments revealed the functions of $P$. brassicae secretory proteins and lay a foundation for additional studies of the mechanisms through which $P$. brassicae interferes with plant immunity.

\section{MATERIALS AND METHODS}

$\boldsymbol{P}$. brassicae and plants. The P. brassicae isolate used in this study was collected from an oilseed rape field located in Yichang city, Hubei Province, China. The club roots were stored at $-80^{\circ} \mathrm{C}$ until resting spore extraction and $P$. brassicae DNA extraction. Nicotiana benthamiana and the hydroponic oilseed rape line ZS11 were grown in a greenhouse at $\sim 22^{\circ} \mathrm{C}$ with a 16 -h light $/ 8$-h dark cycle. Chinese cabbage (Beijing New No. 3) plants were grown on Murashige and Skoog Basal medium at $\sim 22^{\circ} \mathrm{C}$ in total darkness for protoplast preparation.

Transcriptome analysis and prediction of putative secretory proteins. Hydroponic oilseed rape was inoculated with resting spores of $P$. brassicae as described previously (Luo et al. 2014). After seed germination, the seedlings were fastened in 1-cm-thick foam in the top of opaque tubes filled with half-strength Hoagland nutrient solution ( $\mathrm{pH}$ 5.5). Seven days later, the seedlings were inoculated with P. brassicae resting spores at a final concentration of $10^{7} / \mathrm{ml}$. At 3 days postinoculation (dpi), five sets of roots from $P$. brassicae-infected plants were collected for RNA extraction using the TRIzol reagent (Invitrogen) according to the manufacturer's recommended protocol. Five micrograms of total RNA from each sample was subjected to one round of poly-A selection on oligo (dT) Sera-Mag beads, and the resultant messenger RNA was fragmented to an average size of 500 base pairs according to the manufacturer's recommended protocol (Illumina). The manufacturer's (Illumina) recommended protocols were used for first-strand and second-strand complementary DNA (cDNA) synthesis and preparation of the RNA sequencing samples. All of the libraries were sequenced on a HiSeq 2500 instrument to obtain 125-base pairs paired-end reads, and five transcriptome datasets were obtained. For gene expression analysis, the reads were mapped to the P. brassicae e3 genome (accession no. CDSF00000000) (Schwelm et al. 2015) using SOAP, a bioinformation software for sequence assembly and analysis ( $\mathrm{Li}$ et al. 2008) with the default parameters. The uniquely mapped reads were then extracted, and the expression of the unigenes was normalized using the FPKM value.

The protein sequences derived from the $P$. brassicae isolate e3 genome were used for the prediction of secretory proteins. Only those proteins that contained SPs but not additional transmembrane regions and that were $\leq 300$ amino acids were identified as secretory proteins. The SPs were predicted using SignalP v4.1 (Petersen et al. 2011) with sensitive D-cutoff values, and TMHMM v2.0 (Krogh et al. 2001) was then used for the prediction of transmembrane regions based on the protein sequences without SPs.

Assessment of secretory activity directed by SPs from putative secretory proteins in yeast. A yeast signal sequence trap assay was adopted to assess the secretory activity directed by SPs (Jacobs et al. 1997). The DNA sequences encoding SPs were amplified by a high-fidelity DNA polymerase (Tsingke Biotech Co., LTD), and the purified DNA was then cloned into the linearized pSUC2T7M13ORI plasmid using the ClonExpress II One Step Cloning kit (Vazyme Biotech Co., LTD). The primers used in this assay are listed in Supplementary Table S1. The recombinant vectors were transformed into the invertase-negative yeast strain YTK12. Positive clones were used for the assessment of secretory activity through growth assays on YPRAA (a medium containing
$1 \%$ yeast extract, $2 \%$ peptone, $2 \%$ raffinose, $2 \mu \mathrm{g} / \mathrm{ml}$ antimycina, and $2 \%$ agar) plates (with raffinose as the sole carbon source) and through a 2,3,5-triphenyltetrazolium chloride (TTC) assay according to a previous study (Zhang et al. 2018). The transformed yeast can secrete invertase into the extracellular environment and grow on YPRAA plates only if the YTK12 strain is transformed with a pSUC2 vector containing a functional SP, and the secreted invertase can reduce TTC to insoluble, red-colored 1,3,5triphenylformazan (TPF). Otherwise, the yeast is unable to grow on YPRAA plates or reduce TTC to insoluble, red-colored TPF.

Agrobacterium-mediated plant virus transient expression in $N$. benthamiana leaves. Proteins with a functional SP in yeast were tested for the ability to induce or suppress plant cell death triggered by the mouse BAX protein (Lacomme and Cruz 1999) and the cell death inducer from $P$. brassicae as described previously (Wang et al. 2011). The binary potato virus X (PVX) vector pGR107 was used to express genes in $N$. benthamiana. This vector was derived from the pgRenn0000 vector. A $35 \mathrm{~S}$ promoter promoting the transcript of the PVX genome was located between the left and right transfer DNA border sequences, and a multiple clone site was inserted into the coat protein promoter (Wang et al. 2011). The sequences encoding mature secretory proteins (without SPs) were amplified from cDNA (derived from RNAs for transcriptome sequencing) or genomic DNA of $P$. brassicae as the templates. The coding sequence (without introns) was cloned into pGR107 using the ClonExpress II One Step Cloning kit (Vazyme Biotech Co., LTD). The sequenced recombinant plasmids were transformed into Agrobacterium tumefaciens strain GV3101. The positive clones were used for additional injection according to a previously described method (Wang et al. 2011).

To identify the secretory proteins that induced cell death or suppressed cell death triggered by BAX, the optical density (OD) 600 value of the $A$. tumefaciens suspension was adjusted to 0.4 , and A. tumefaciens carrying pGR107-BAX was injected $12 \mathrm{~h}$ after the injection of $A$. tumefaciens carrying secretory protein-encoding genes. For the screening of secretory proteins that suppress cell death induced by PBCN_002550, the $\mathrm{OD}_{600}$ value of the A. tumefaciens suspension was adjusted to 1.0. Equal amounts of A. tumefaciens carrying pGR107PBCN_002550 and A. tumefaciens carrying genes encoding other secretory proteins were mixed and injected into $N$. benthamiana leaves. The necrosis of $N$. benthamiana leaves was investigated $7 \mathrm{dpi}$ of the genus Agrobacterium carrying pGR107-BAX or the mixture of the genus Agrobacterium carrying pGR107-PBCN_002550 and genes encoding other secretory proteins. $N$. benthamiana leaves injected with the genus Agrobacterium carrying pGR107-eGFP were used as a negative control.

The expression levels of the secretory proteins and BAX were assessed by western blotting. BAX was fused with an HA tag, and thus, an anti-HA tag antibody (Sigma-Aldrich) was used for BAX detection. The secretory proteins were fused with an FLAG tag, and an anti-FLAG tag antibody (Sigma-Aldrich) was used for the detection of secretory proteins. The $N$. benthamiana leaves injected with the genus Agrobacterium carrying pGR107 were used as a negative control for detection of the unspecific binding of the antibody.

Detection of $\mathrm{H}_{2} \mathrm{O}_{2}$ accumulation and quantification of electrolyte leakage. The accumulation of $\mathrm{H}_{2} \mathrm{O}_{2}$ was detected by 3,3'-diaminobenzidine (DAB) staining (Thordal-Christensen et al. 1997). Whole $N$. benthamiana leaves were harvested at 3 dpi with A. tumefaciens and soaked in $1 \mathrm{mg} / \mathrm{ml}$ of DAB solution (pH 3.8) at room temperature. Eight hours later, the leaves were discolored by boiling in $95 \%$ ethanol for $15 \mathrm{~min}$, cleared with $2.5 \mathrm{mg} / \mathrm{ml}$ of trichloroacetic aldehyde solution, and photographed. The degree of electrolyte leakage was quantified at $7 \mathrm{dpi}$. Leaf discs $\sim 1 \mathrm{~cm}$ in diameter were harvested and soaked in $5 \mathrm{ml}$ of double-distilled water for $3 \mathrm{~h}$, and the electrical conductivity was then quantified and recorded as E1. The leaf discs were boiled in double-distilled water for $25 \mathrm{~min}$. After cooling to room temperature, the electrical conductivity was quantified and recorded as E2. The degree of 
electrolyte leakage was calculated as follows: electrolyte leakage $=$ E1/E2 × 100\% (Mittler et al. 1999).

Protoplast preparation and transformation. The vectors used for protoplast transformation were derived from pGL3 control (Groskreutz et al. 1995). The SV40 promoter was replaced by the $35 \mathrm{~S}$ promoter from the pBI121 vector (Chen et al. 2003). DNA fragments containing the $35 \mathrm{~S}$ gene Tnos sequence were inserted between the SalI and BamHI restriction enzyme sites using the ClonExpress II One Step cloning kit (Vazyme Biotech Co., LTD). The recombinant plasmids were then extracted using an EndoFree Maxi Plasmid kit (TIANGEN Biotech Co., LTD) and adjusted to $2 \mathrm{mg} / \mu \mathrm{l}$ for transformation.

The hypocotyls of Chinese cabbage were collected for protoplast preparation according to the method described previously (Cheng et al. 1994b) with several modifications. Seven-day-old hypocotyls were harvested. The hypocotyls were cut in half along the longitudinal axis, and then, they were cut into $1-\mathrm{cm}$ segments. The segments were plasmolyzed in cell and protoplast washing (CPW) solution $\left(27.2 \mathrm{mg} / \mathrm{liter}\right.$ of $\mathrm{KH}_{2} \mathrm{PO}_{4}, 101.0 \mathrm{mg} / \mathrm{liter}$ of $\mathrm{KNO}_{3}$, $1,480.0 \mathrm{mg} / \mathrm{liter}$ of $\mathrm{CaCl}_{2} \cdot 2 \mathrm{H}_{2} \mathrm{O}, 246.0 \mathrm{mg} / \mathrm{liter}$ of $\mathrm{MgSO}_{4} \cdot 7 \mathrm{H}_{2} \mathrm{O}$, $0.025 \mathrm{mg} / \mathrm{liter}$ of $\mathrm{CuSO} 4 \cdot 5 \mathrm{H}_{2} \mathrm{O}$, and $0.16 \mathrm{mg} / \mathrm{liter}$ of $\mathrm{KI}$, $\mathrm{pH} 5.6$ ) supplemented with $13 \%$ mannitol for $\sim 1 \mathrm{~h}$; transferred into CPW solution supplemented with $9 \%$ mannitol solution containing $2 \%$ (wt/vol) Rhozyme, 4\% Meicelase, and 0.3\% Macerozyme; and incubated overnight at $25^{\circ} \mathrm{C}$. The impurities were filtered by passing the solution through a cell strainer, and the protoplasts were centrifuged at $100 \times g$ for 5 min and further cleaned by suspension in CPW solution supplemented with $20 \%$ sucrose. Approximately $20 \mu \mathrm{g}$ of plasmid was subsequently transformed into clean protoplasts through polyethylene glycol-mediated transformation according to the method described previously (Cheng et al. 1994a). After incubation for $24 \mathrm{~h}$ at $26^{\circ} \mathrm{C}$, the transformed protoplasts were harvested for the quantification of luciferase (LUC) activity using an LUC reporter kit (Beyotime Biotech Co., LTD) according to the technical manual.

In this system, the gene was coexpressed with $L U C$ in Chinese cabbage hypocotyl cells. If the protein can induce cell death, low LUC expression will be obtained, and sufficiently low chemiluminescence cannot be detected (Yoshida et al. 2009). Therefore, the capacity to induce cell death of a gene can be quantified by measuring the LUC activity and subsequent chemiluminescence intensity.

\section{RESULTS}

Fifty-three genes encoding putative secretory proteins of $P$. brassicae were expressed during primary infection. The transcriptome analysis revealed different FPKM values (Supplementary Table S2) in the five transcriptome datasets (all from the infected roots at 3 days after inoculation with $P$. brassicae; Sequence Read Archive accession no. PRJNA527625). The genes with FPKM values greater than zero in more than three transcriptomes were considered to be expressed during primary infection. After the prediction of secretory proteins, 53 genes encoding putative secretory proteins were considered to be expressed during primary infection. Among these 53 genes encoding putative secretory proteins, 6 (PBCN_000422, PBCN_000804, PBCN_004558, PBCN_006805, PBCN_ 0008074 , and PBCN_008892) were partial genes, and 2 ( $P B C N_{-}$ 005498 and PBCN_009221) could not be cloned. Ultimately, 45 genes were obtained and used for subsequent experiments.

SPs from 33 genes directed secretory activity in yeast. The secretory activity directed by the SPs in the 45 candidate genes was tested individually. Thirty-three of these SP sequences showed secretory activity in yeast as demonstrated by the growth assay on YPRAA plates and the TTC assay. Two typical SPs ( $P B C N \_007868$ and $P B C N \_009214$ ) with secretory activity in yeast are shown in Figure 1. Similar to the positive control (containing the SP of PS87) (Gu et al. 2011), the transformed yeast grew normally on YPRAA plates and produced insoluble, red-colored TPF in the TTC assay. The SP sequences of the remaining 12 genes were considered to not direct secretory activity in the yeast assay. Two typical results (the SPs from PBCN_004660 and PBCN_007663) are shown in Figure 1. The transformed yeast exhibited weak growth on YPRAA plates but could not convert the colorless TTC solution to the insoluble, red-colored TPF, which was similar to the results obtained for the negative control (containing the SP of $M g 87)(\mathrm{Gu}$ et al. 2011). Therefore, only the 33 genes containing active secretory SPs in yeast (Supplementary Fig. S1) were considered secretory proteins and used in subsequent studies.

Two secretory proteins induced cell death in $N$. benthamiana. To identify whether these 33 proteins could induce cell death, each gene was transiently expressed in the leaves of $N$. benthamiana using the Agrobacterium-mediated plant virus

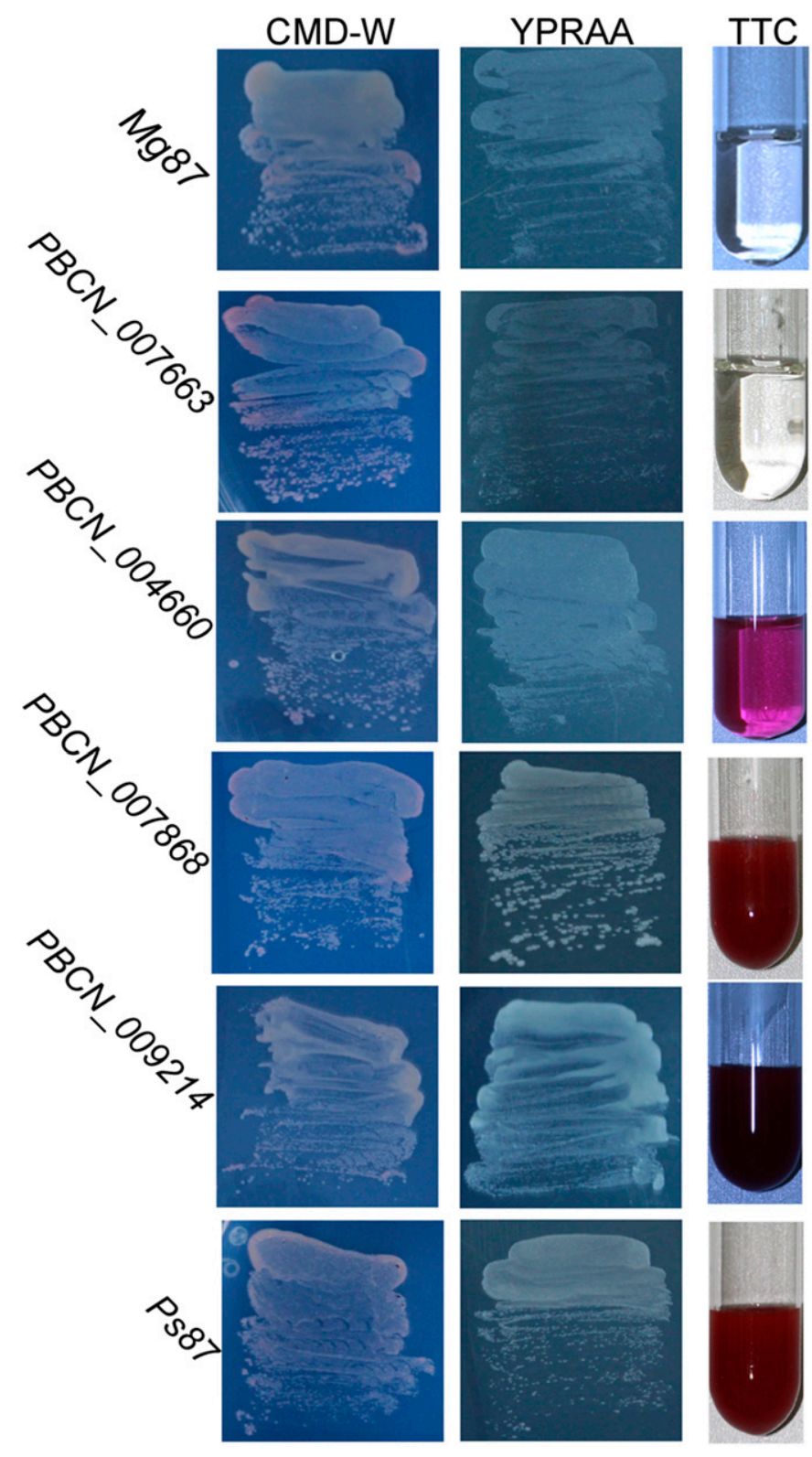

Fig. 1. Functional validation of signal peptides from putative secretory proteins of Plasmodiophora brassicae. Two active signal peptides (SPs) from putative secretory proteins (PBCN_007868 and PBCN_009214) and two inactive SPs from putative secretory proteins (PBCN_004660 and PBCN_007663) are listed. SPs from Phytophthora sojae Avr1b were used as the positive control, and Magnaporthe oryzae Mg87 served as the negative control. CMD-W: $0.67 \%$ YNB, $0.075 \%$ tryptophan dropout supplement, $2 \%$ sucrose, $0.1 \%$ glucose, and $2 \%$ agar. YPRAA: $1 \%$ yeast extract, $2 \%$ peptone, $2 \%$ raffinose, $2 \mu \mathrm{g} / \mathrm{ml}$ antimycina, and $2 \%$ agar. TTC, triphenyltetrazolium chloride. 
transient expression system, and leaf necrosis was investigated at 7 dpi. Similar to the positive control (leaves expressing $B A X$ ), necrosis was found on the leaves expressing the secretory proteins encoded by the PBCN_O02550 and PBCN_005499 genes, which indicated that these two secretory proteins could induce cell death in $N$. benthamiana leaves (Fig. 2A). Although no necrosis was found in the negative control (leaves expressing eGFP), only a little yellowing was found. The leaves expressing other secretory genes are shown in Supplementary Figure S2. In addition, $N$. benthamiana leaves expressing $e G F P, B A X, P B C N \_002550$, and PBCN_005499 were photographed at 3,5 , and $7 \mathrm{dpi}$. Severe necrosis emerged at 3 dpi on $N$. benthamiana leaves expressing BAX. Although necrosis was observed at $5 \mathrm{dpi}$ on $N$. benthamiana leaves expressing $P B C N_{-}$ 002550 , only chlorosis was observed on $N$. benthamiana leaves expressing PBCN_005499 (Fig. 2A). Compared with the effects of BAX expression, the $N$. benthamiana leaves expressing

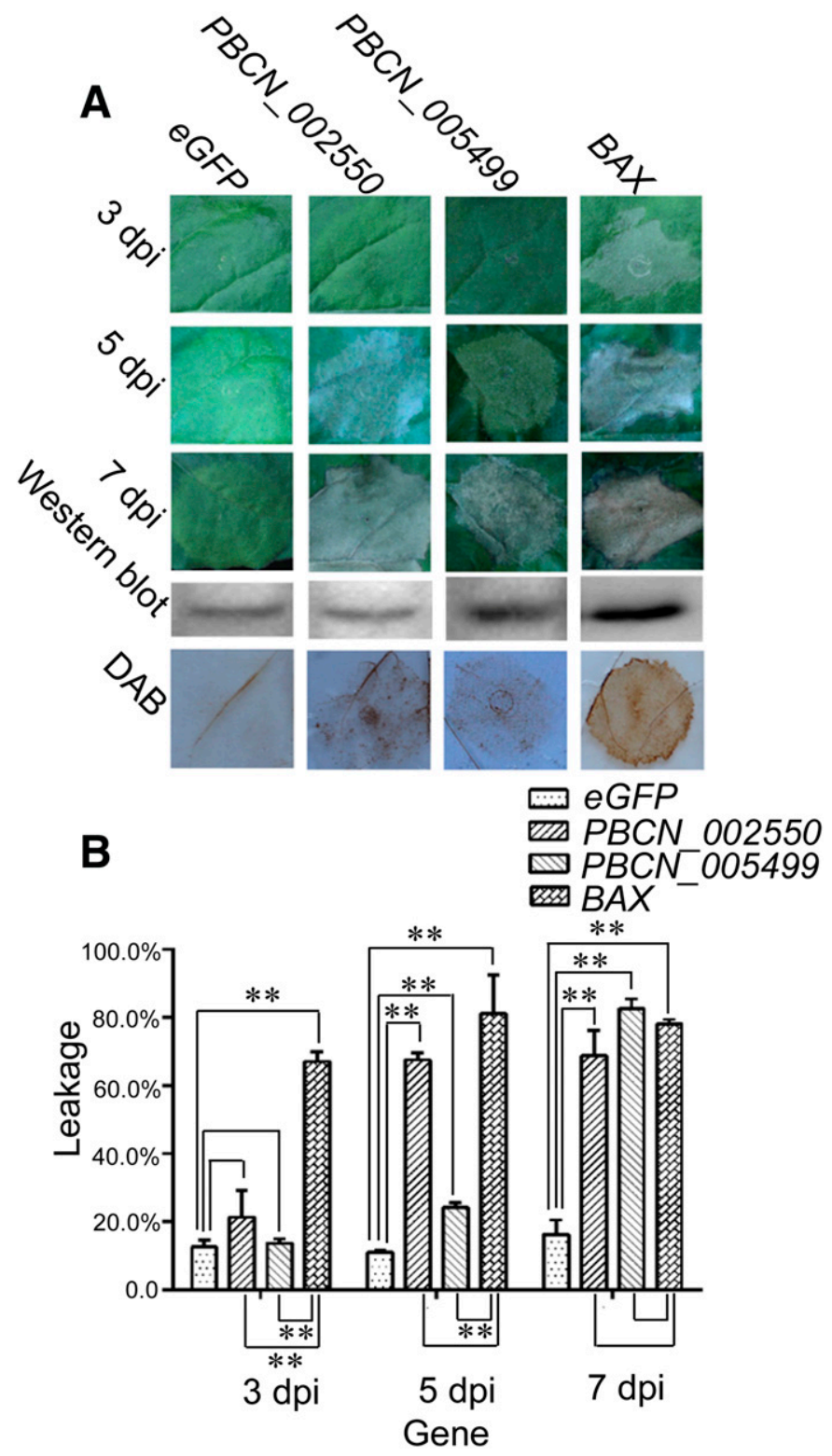

Fig. 2. Secretory proteins of Plasmodiophora brassicae induced programmed cell death, $\mathrm{H}_{2} \mathrm{O}_{2}$ accumulation, and electrolyte leakage in Nicotiana benthamiana. A, Necrosis and $\mathrm{H}_{2} \mathrm{O}_{2}$ accumulation in $N$. benthamiana leaves expressing eGFP, PBCN_002550, PBCN_005499, and BAX. B, Electrolyte leakage at 3,5 , and 7 days postinoculation (dpi) from $N$. benthamiana leaves expressing eGFP, PBCN_002550, PBCN_005499, and BAX. DAB, 3,3'-diaminobenzidine. ** indicates $P<0.01$.
PBCN_002550 and PBCN_005499 showed decreased cell death and delayed necrosis, which indicated that the proteins encoded by these two genes induced cell death less effectively than BAX in N. benthamiana.

Cell death is often associated with $\mathrm{H}_{2} \mathrm{O}_{2}$ accumulation, electrolyte leakage, and other metabolic abnormalities (Bai et al. 2012; Wojtaszek 1997). N. benthamiana leaves expressing $P B C N_{-}$ $002550, P B C N \_0005499, B A X$, and $e G F P$ were harvested at 3 dpi for DAB staining. Brown substances showing $\mathrm{H}_{2} \mathrm{O}_{2}$ accumulation were detected in leaves expressing $P B C N_{-} 002550, P B C N_{-}$ 0005499 , and $B A X$ but were not detected in leaves expressing $e G F \bar{P}$ (Fig. 2A). Moreover, leaves expressing $B A X$ were stained a deeper color. The degree of electrolyte leakage from $N$. benthamiana leaves expressing these genes was quantified at 3,5, and $7 \mathrm{dpi}$. None of the $P$. brassicae secretory proteins induced significant leakage at 3 dpi. However, leaves expressing PBCN_002550 and $P B C N_{-}$ 005499 showed significant leakage at 5 and 7 dpi compared with leaves expressing $e G F P$, and leaves expressing PBCN_005499 showed significantly reduced leakage at 5 dpi compared with leaves expressing PBCN_O02550 and BAX (Fig. 2B). These results were consistent with the results described above and indicated that both PBCN_002550 and PBCN_0005499 were weak inducers of cell death and that PBCN_0005499 was a weaker inducer than $P B C N_{-}$ 0002550 .

PBCN_002550 induced cell death in Chinese cabbage hypocotyls. The whole lifecycle of $P$. brassicae can occur only in cruciferous plants and not in other plants, such as $N$. benthamiana.

A
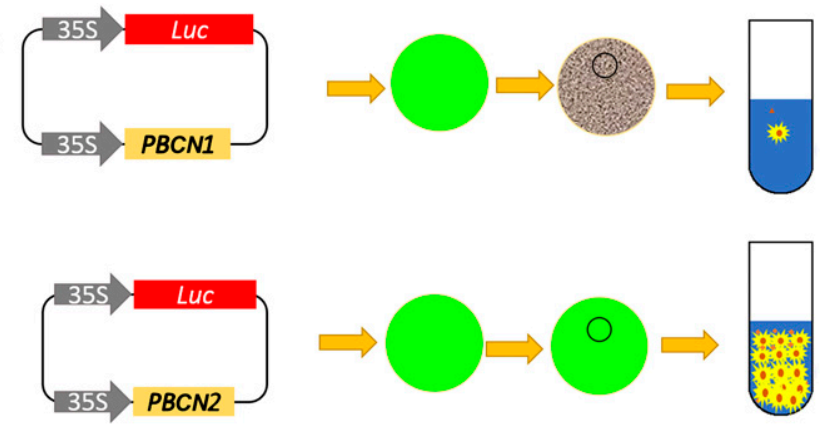

B

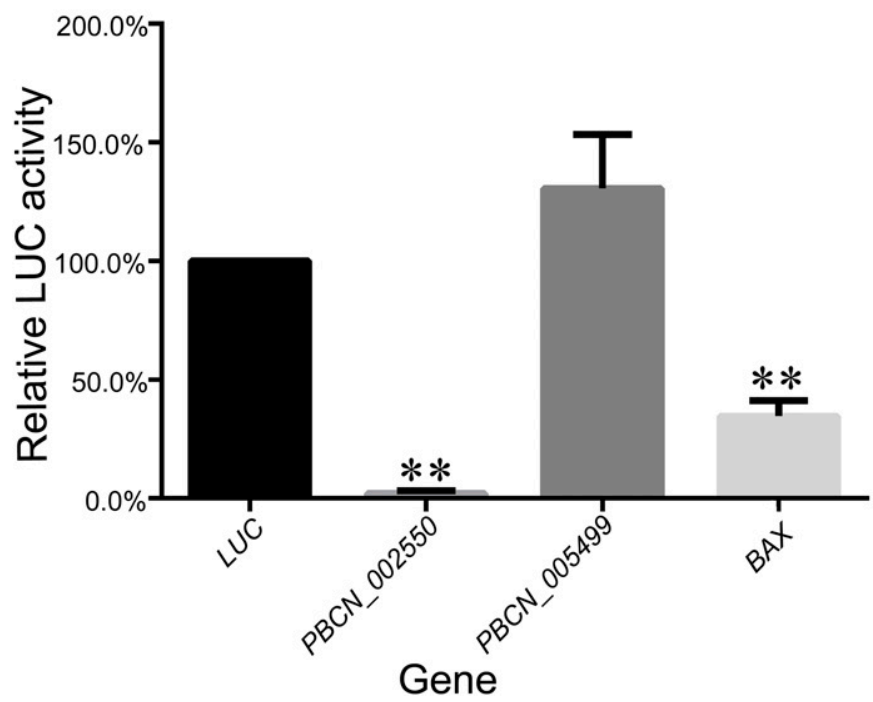

Fig. 3. PBCN_002550 induces cell death in Chinese cabbage hypocotyls. A, Scheme of the experimental protoplast transformation of Chinese cabbage hypocotyls. The lethal gene causes rapid cell death, resulting in little luciferase (LUC) activity and low chemiluminescence intensity. B, Chemiluminescence intensity of protoplasts coexpressing PBCN_002550, PBCN_005499, or BAX with $L U C$. ** indicates $P<0.01$. 
A firefly LUC coexpression system was adopted to further assess whether PBCN_002550 and PBCN_0005499 can induce cell death in host plant cells. Compared with protoplasts expressing only $L U C$ (control), protoplasts coexpressing PBCN_002550 and $L U C$ exhibited significantly decreased $(P<0.01)$ chemiluminescence intensity (Fig. 3B). However, the chemiluminescence intensity of protoplasts coexpressing PBCN_O05499 and $L U C$ was not significantly different from that of the control protoplasts, which indicated that only PBCN_002550 could induce cell death in Chinese cabbage hypocotyls.

Twenty-four secretory proteins suppressed BAXinduced cell death. Among the 31 tested secretory protein genes, $N$. benthamiana leaves expressing 7 secretory protein-encoding genes (PBCN_001856, PBCN_003620, PBCN_005440, PBCN_ $007081, P B C N \_008608, P B \bar{C} N \_009251$, and $\left.P B C N \_009622\right)$ exhibited a similar level of necrosis as leaves expressing $e G F P$ and $B A X$ (negative control), which indicated that these 7 secretory protein-encoding genes could not suppress BAX-induced cell death. In contrast to the results obtained for these 7 genes, the levels of necrosis were noticeably reduced on $N$. benthamiana leaves expressing the other 24 secretory proteins (Fig. 4A). PBCN_001987 showed a typical suppression of BAX-triggered cell death as illustrated in Figure 4B. The suppression effect of these proteins on BAX-triggered cell death was further confirmed by the coinfiltration of the genus Agrobacterium carrying putative cell death inhibitors and diluted (32-fold, $\mathrm{OD}_{600}=0.0125$ ) genus Agrobacterium carrying BAX.

To quantify the level of cell death suppression by these secretory proteins, the electrolyte leakage from $N$. benthamiana leaves at 7 dpi was quantified. Compared with $N$. benthamiana leaves expressing $e G F P, N$. benthamiana leaves expressing eight genes (PBCN_001856, PBCN_003620,PBCN_005440,PBCN_007081, $P B C N \_008608, P B C N \_009251, P B C N \_009331$, and $P B C N_{-}$ 009622) exhibited no significant reduction in electrolyte leakage. Among $N$. benthamiana leaves expressing these eight genes, $N$. benthamiana expressing PBCN_009331 did not exhibit obvious cell death. Unlike these eight genes, however, the other 23 genes significantly suppressed electrolyte leakage induced by BAX

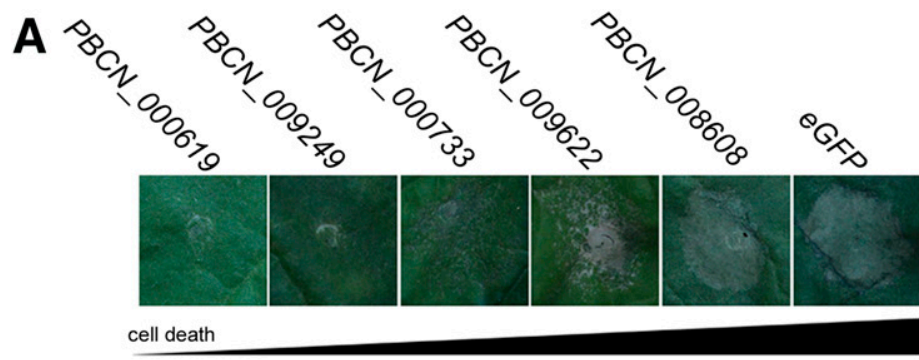

B

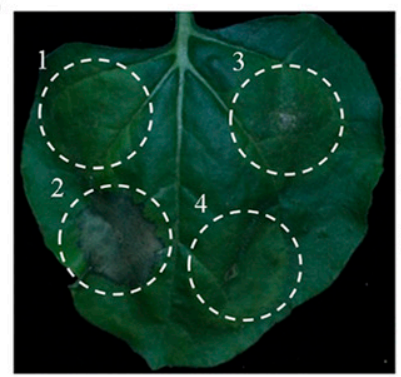

1 PBCN_001987

$2 B A X$

3 PBCN_001987 $\rightarrow 12 \mathrm{~h} \rightarrow$ BAX

4 PBCN_001987 $\rightarrow 24 \mathrm{~h} \rightarrow B A X$

Western blot of 3

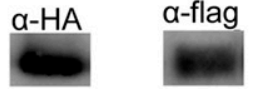

C

$100.0 \%$
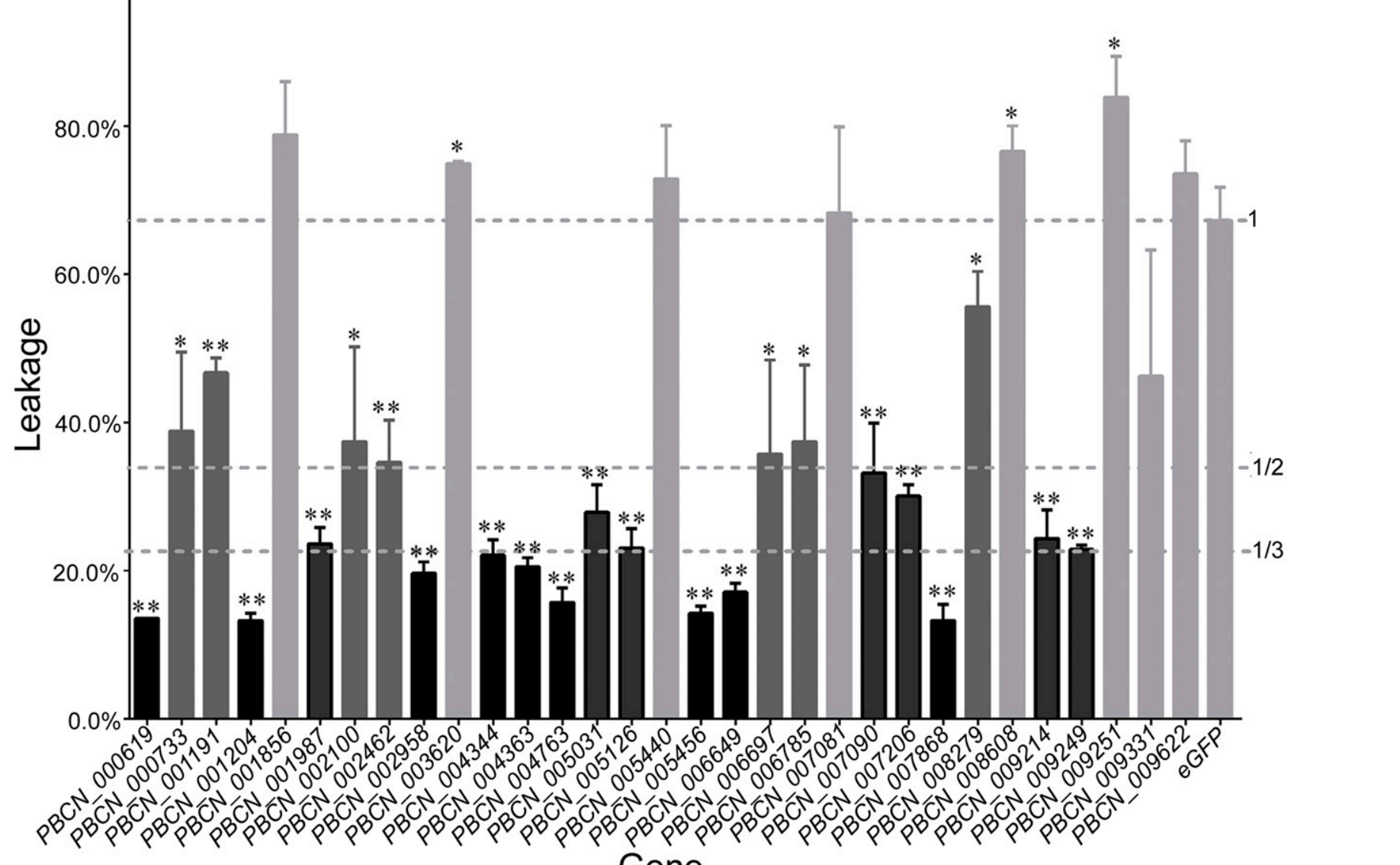

Gene

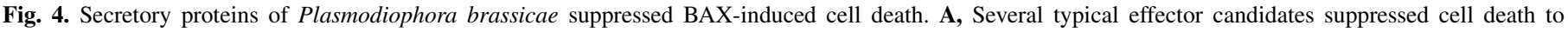

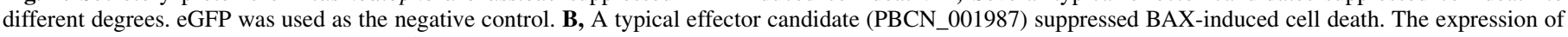

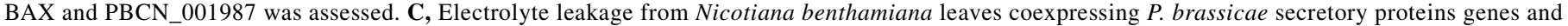
$B A X$. $\alpha$-HA, HA tag antibody. $\alpha$-flag, flag tag antibody. $*$ indicates $0.01<P<0.05$; and $* *$ indicates $P<0.01$. 
expression. Among these 23 genes, 16 reduced the degree of electrolyte leakage to less than one-half of that found in the negative control. In addition, nine genes reduced the level of electrolyte leakage to less than one-third of that found in the negative control (Fig. 4C).

Twenty-eight secretory proteins suppressed PBCN 002550-induced cell death. PBCN_002550 was the only secretory protein that could induce cell death in both $N$. benthamiana leaves and Chinese cabbage hypocotyls. An additional screen of secretory proteins suppressing PBCN_002550-induced cell death was performed. In contrast to the protocol used for the BAX-induced cell death suppression assay, equal amounts of the genus Agrobacterium carrying pGR107-secretory protein-encoding gene constructs and the genus Agrobacterium carrying pGR107$P B C N \_002550$ were coinjected into $N$. benthamiana leaves. Subsequently, the presence of necrosis on $N$. benthamiana leaves was investigated at $7 \mathrm{dpi}$. Similar to the negative control
( $N$. benthamiana leaves coinjected with the genus Agrobacterium carrying pGR107-eGFP and pGR107-PBCN_002550), N. benthamiana leaves expressing PBCN_001856, PBCN_008608, and PBCN_009622 showed severe necrosis. Unlike $N$. benthamiana leaves expressing these 3 genes, $N$. benthamiana leaves expressing the other 28 genes exhibited different degrees of necrosis reduction (Fig. 5A). No visible necrosis was observed in $N$. benthamiana leaves expressing PBCN_000619,PBCN_001987,PBCN_4363,PBCN_004708, and $P B C N \_005126$. The typical cell death suppression effect of PBCN_ 005126 is shown in Figure 5B. The degree of electrolyte leakage from these $N$. benthamiana leaves was also quantified. The necrotic $N$. benthamiana leaves expressing PBCN_001856,PBCN_008608, or $P B C N \_009622$ showed high electrolyte leakage, similar to $N$. benthamiana leaves expressing $e G F P$, which indicated that these three genes could not suppress electrolyte leakage induced by PBCN_002550. Similar to N. benthamiana leaves expressing these three genes, the degree of electrolyte leakage from $N$. benthamiana
A

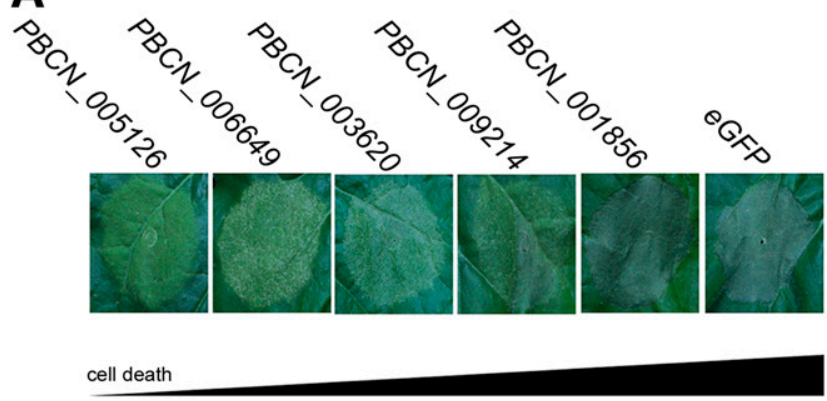

B

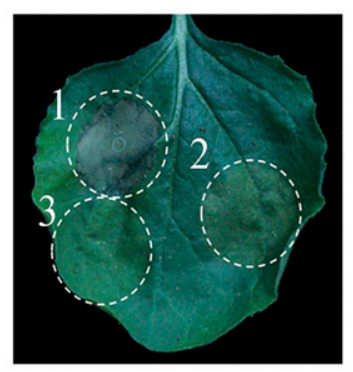

1 PBCN_002550

2 PBCN_002550 $\rightarrow 0 \mathrm{~h} \rightarrow P B C N \_005126$ 3 PBCN_005126

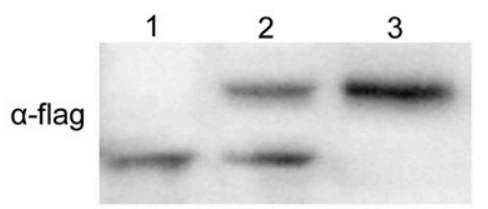

C

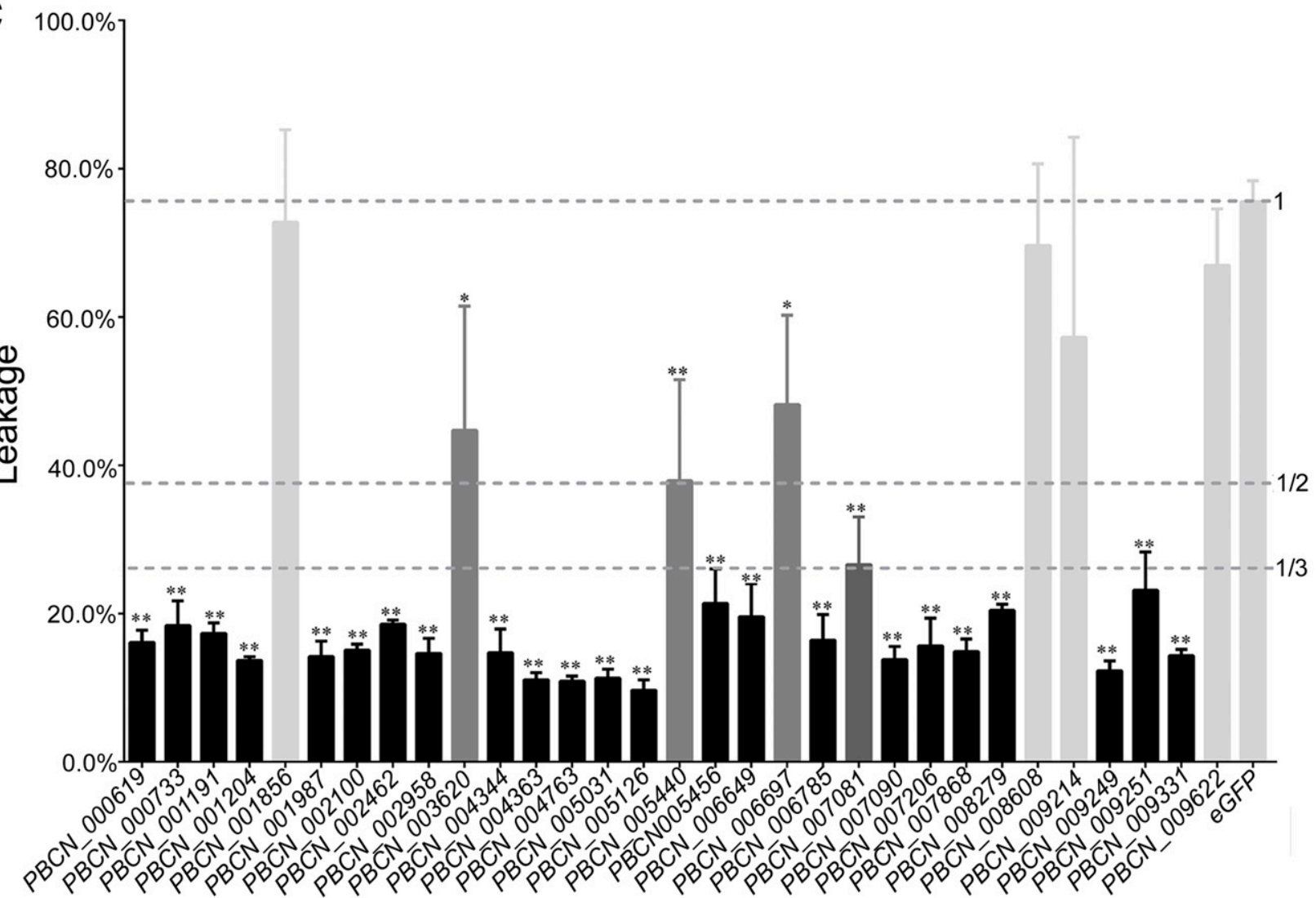

Gene

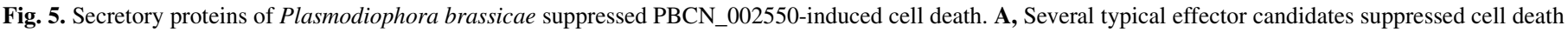

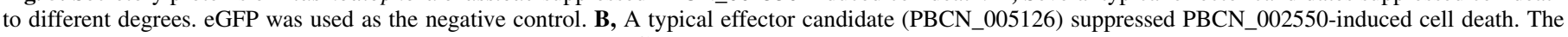

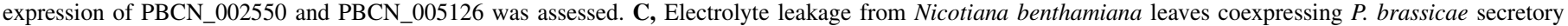
proteins genes and $P B C N \_002550 . \alpha$-flag, flag tag antibody. $*$ indicates $0.01<P<0.05$; and $* *$ indicates $P<0.01$. 
leaves expressing PBCN_009214 was not significantly different from the negative control. In contrast to the results obtained for these 4 genes, the electrolyte leakage from $N$. benthamiana leaves expressing the other 27 genes was significantly different $(P<0.01)$ from that of the negative control. Specifically, the electrolyte leakage from $N$. benthamiana leaves expressing 23 genes was reduced to less than one-third of that of the negative control (Fig. 5C).

\section{DISCUSSION}

The disease cycle of $P$. brassicae comprises two phases: the primary phase, which occurs in the root hairs, and the secondary phase, which occurs in the root cortex (Kageyama and Asano 2009). According to previous studies, the recognition of $P$. brassicae by the host occurs during the primary phase (McDonald et al. 2014). However, the mechanism through which plants recognize $P$. brassicae and the mechanism through which $P$. brassicae manipulates the plant immune response to achieve successful infection remain unclear. To reveal these mechanisms, we systematically screened the secretory protein-encoding genes expressed by $P$. brassicae during primary infection and investigated their ability to suppress or trigger plant cell death.

Secretory proteins are effector candidates that are critical for pathogen infection. Therefore, the accurate identification of secretory proteins is important for studying their functions. A common identification method involves the combination of predictions using bioinformatics software with yeast signal sequence trap assays (Gu et al. 2011; Krijger et al. 2008; Yeom et al. 2011). This strategy was adopted in this study, and a sensitive Dcutoff value (0.34) was selected for SP sequence prediction using SignalP v4.1.

Surprisingly, we found that the secretory protein PBCN_002550 can induce cell death in Chinese cabbage hypocotyls. Because $P$. brassicae is an intracellular biotrophic parasite, it needs to absorb nutrients from living hosts, and cell death seems to be detrimental to its propagation. However, cell death-inducing genes are widely spread in plant pathogen species. Avh241 from Phytophthora sojae

TABLE 1. Details of putative secretory proteins

\begin{tabular}{|c|c|c|c|c|c|c|c|c|c|c|c|}
\hline \multirow[b]{3}{*}{ Proteins } & \multirow[b]{3}{*}{ e3 homolog } & \multirow[b]{3}{*}{$\begin{array}{l}\text { Functional } \\
\text { domains }\end{array}$} & \multirow[b]{3}{*}{$\begin{array}{l}\text { Identity } \\
(\%)\end{array}$} & \multirow{3}{*}{$\begin{array}{c}\text { Functional } \\
\text { SignalP in } \\
\text { yeast }\end{array}$} & \multicolumn{3}{|c|}{ Induce cell death } & \multicolumn{4}{|c|}{ Suppress cell death } \\
\hline & & & & & \multicolumn{2}{|c|}{$\begin{array}{l}\text { In Nicotiana } \\
\text { benthamiana }\end{array}$} & \multirow{2}{*}{$\begin{array}{c}\text { In Chinese } \\
\text { cabbage: } \\
\text { necrosis }\end{array}$} & \multicolumn{2}{|c|}{ BAX induced } & \multicolumn{2}{|c|}{$\begin{array}{l}\text { PBCN_002550 } \\
\text { induced }\end{array}$} \\
\hline & & & & & Necrosis & $\begin{array}{l}\text { Leakage } \\
(\%)\end{array}$ & & Necrosis & $\begin{array}{l}\text { Leakage } \\
(\%)\end{array}$ & Necrosis & $\begin{array}{l}\text { Leakage } \\
(\%)\end{array}$ \\
\hline PBCN_000548 & CEO97203.1 & No & 100 & No & $-^{\mathrm{a}}$ & - & - & - & - & - & - \\
\hline PBCN_000619 & CEO97274.1 & No & 98.62 & Yes & No & - & - & Yes & $13.6 \pm 0.03$ & Yes & $16.1 \pm 1.6$ \\
\hline PBCN_000733 & CEO97388.1 & recA & 99.34 & Yes & No & - & - & Yes & $38.9 \pm 10.7$ & Yes & $18.4 \pm 3.3$ \\
\hline PBCN_001191 & CEO99285.1 & No & 100 & Yes & No & - & - & Yes & $46.7 \pm 2.0$ & Yes & $17.3 \pm 1.4$ \\
\hline PBCN_001204 & CEO99298.1 & ANK & 91.45 & Yes & No & - & - & Yes & $13.3 \pm 1.0$ & Yes & $13.7 \pm 0.5$ \\
\hline PBCN_001442 & CEP00388.1 & HflC & 100 & No & - & - & - & - & - & - & - \\
\hline PBCN_001454 & CEP00400.1 & No & 99.66 & No & - & - & - & - & - & - & - \\
\hline PBCN_001856 & CEP01250.1 & No & 100 & Yes & No & - & - & No & $78.8 \pm 7.2$ & No & $72.8 \pm 12.5$ \\
\hline PBCN_001987 & CEP01381.1 & zf-MYND & 100 & Yes & No & - & - & Yes & $23.6 \pm 2.1$ & Yes & $14.2 \pm 2.1$ \\
\hline PBCN_002100 & CEP01496.1 & SMC_prok_A & 100 & Yes & No & - & - & Yes & $37.4 \pm 12.8$ & Yes & $15.1 \pm 0.8$ \\
\hline PBCN_002462 & CEP02197.1 & No ${ }^{-1}-$ & 98.91 & Yes & No & - & - & Yes & $34.6 \pm 5.7$ & Yes & $18.6 \pm 0.5$ \\
\hline PBCN_002550 & CEP02583.1 & No & 100 & Yes & Yes & $69.8 \pm 7.4$ & Yes & - & - & - & - \\
\hline PBCN_002958 & CEP03198.1 & ChtBD1 & 99.42 & Yes & No & - & - & Yes & $19.6 \pm 1.6$ & Yes & $14.6 \pm 2.0$ \\
\hline PBCN_003236 & CEP03476.1 & PRE1 & 100 & No & - & - & - & - & - & - & - \\
\hline PBCN_003620 & CEO94807.1 & No & 99.14 & Yes & No & - & - & No & $74.9 \pm 0.3$ & Yes & $44.7 \pm 16.8$ \\
\hline PBCN_004344 & CEO95618.1 & No & 91.4 & Yes & No & - & - & Yes & $22.1 \pm 2.1$ & Yes & $14.7 \pm 3.2$ \\
\hline PBCN_004363 & CEO95637.1 & No & 100 & Yes & No & - & - & Yes & $20.6 \pm 1.2$ & Yes & $11.1 \pm 1.0$ \\
\hline PBCN_004660 & CEO95970.1 & No & 100 & No & - & - & - & - & - & - & - \\
\hline PBCN_004708 & CEO96018.1 & Ribosomal_P2 & 100 & No & - & - & - & - & - & - & - \\
\hline PBCN_004763 & CEO96073.1 & PRK14510 & 100 & Yes & No & - & - & Yes & $15.7 \pm 1.9$ & Yes & $10.9 \pm 0.7$ \\
\hline PBCN_005031 & CEO96360.1 & No & 100 & Yes & No & - & - & Yes & $27.9 \pm 3.7$ & Yes & $11.3 \pm 1.2$ \\
\hline PBCN_005126 & CEO96517.1 & vWFA & 100 & Yes & No & - & - & Yes & $23.1 \pm 2.6$ & Yes & $9.6 \pm 1.4$ \\
\hline PBCN_005440 & CEO96836.1 & No & 98.87 & Yes & No & - & - & No & $72.9 \pm 7.2$ & Yes & $37.9 \pm 13.6$ \\
\hline PBCN_005456 & CEO96852.1 & Ank_2, WD40 & 99.61 & Yes & No & - & - & Yes & $14.3 \pm 1.0$ & Yes & $21.4 \pm 4.7$ \\
\hline PBCN_005499 & CEO96895.1 & No & 100 & Yes & Yes & $82.6 \pm 2.9$ & No & - & - & - & - \\
\hline PBCN_005691 & CEO97087.1 & No & 97.5 & No & - & - & - & - & - & - & - \\
\hline PBCN_006649 & CEO98535.1 & Ank_4 & 90.71 & Yes & No & - & - & Yes & $17.1 \pm 1.2$ & Yes & $19.6 \pm 4.5$ \\
\hline PBCN_006655 & CEO98541.1 & ANK & 99.68 & No & - & - & - & - & - & - & - \\
\hline PBCN_006697 & CEO98583.1 & ANK & 98.43 & Yes & No & - & - & Yes & $35.7 \pm 12.7$ & Yes & $48.2 \pm 12.1$ \\
\hline PBCN_006785 & CEO98671.1 & eIF3_subunit & 99.22 & Yes & No & - & - & Yes & $37.4 \pm 10.4$ & Yes & $16.4 \pm 3.4$ \\
\hline PBCN_007081 & CEO98967.1 & Tyrosinase & 100 & Yes & No & - & - & No & $68.3 \pm 11.6$ & Yes & $26.6 \pm 6.4$ \\
\hline PBCN_007090 & CEO98976.1 & CDA1 & 100 & Yes & No & - & - & Yes & $33.2 \pm 6.7$ & Yes & $13.8 \pm 1.8$ \\
\hline PBCN_007206 & CEO99092.1 & pntA & 99.46 & Yes & No & - & - & Yes & $30.1 \pm 1.5$ & Yes & $15.6 \pm 3.7$ \\
\hline PBCN_007663 & CEO99929.1 & alkPPc & 100 & No & - & - & - & - & - & - & - \\
\hline PBCN_007856 & CEP00122.1 & zf-RING_2 & 100 & No & - & - & - & - & - & - & - \\
\hline PBCN_007868 & CEP00134.1 & Lactamase_B & 98.02 & Yes & No & - & - & Yes & $13.2 \pm 2.2$ & Yes & $14.9 \pm 1.7$ \\
\hline PBCN_008279 & CEP00967.1 & No & 99.13 & Yes & No & - & - & Yes & $55.6 \pm 4.8$ & Yes & $20.4 \pm 0.8$ \\
\hline PBCN_008608 & CEP01666.1 & No & 100 & Yes & No & - & - & No & $76.6 \pm 3.5$ & No & $69.6 \pm 11.0$ \\
\hline PBCN_009214 & CEP02996.1 & RING & 100 & Yes & No & - & - & Yes & $24.4 \pm 3.9$ & Yes & $57.2 \pm 27$ \\
\hline PBCN_009249 & CEP03031.1 & ANK & 82.59 & Yes & No & - & - & Yes & $22.9 \pm 0.6$ & Yes & $12.3 \pm 1.3$ \\
\hline PBCN_009251 & CEP03033.1 & ANK & 87.17 & Yes & No & - & - & No & $83.9 \pm 5.5$ & Yes & $23.2 \pm 5.1$ \\
\hline PBCN_009331 & CEP03113.1 & CLECT & 100 & Yes & No & - & - & Yes & $46.2 \pm 17.0$ & Yes & $14.3 \pm 0.8$ \\
\hline PBCN_009387 & CEP03502.1 & Ribosomal_L22 & 100 & No & - & - & - & - & - & - & - \\
\hline PBCN_009622 & CEO95090.1 & No & 100 & Yes & No & - & - & No & $73.6 \pm 4.5$ & No & $67.0 \pm 7.6$ \\
\hline PBCN_009670 & CEO95403.1 & $\mathrm{C} 2 \mathrm{H} 2 \mathrm{Zn}$ finger & 100 & No & - & - & - & - & - & - & - \\
\hline
\end{tabular}

a Dashes indicate unknown. 
(Yu et al. 2012), PvRxLR16 from Plasmopara viticola (Xiang et al. 2016), and Las5315mp from 'Candidatus Liberibacter asiaticus' (Pitino et al. 2016) reportedly induce cell death in N. benthamiana and other plants. These results suggest that these genes might have other functions. Moreover, because the plant materials used in these studies were susceptible cultivars, these gene products might be recognized not by resistant genes but by some intracellular nucleotide-binding domains or NB-LRR immune receptors (Pitino et al. 2016).

In addition to PBCN_002550, the secretory protein PBCN 005499 induced cell death in $N$. benthamiana but not in Chinese cabbage hypocotyls. Chinese cabbage is the host of $P$. brassicae, whereas $N$. benthamiana is a nonhost. The different responses induced by PBCN_005449 reflected the different interactions of $P$. brassicae with host and nonhost plants.

Although $P$. brassicae has secretory proteins that can induce cell death in the host, cell death might not occur. Of the 31 tested secretory proteins, 28 suppressed PBCN_002550-induced cell death, and 24 suppressed BAX-induced cell death. This finding indicated that $P$. brassicae encodes a large number of proteins that can suppress plant immunity. This phenomenon has also been found in other biotrophic pathogens. Of the 83 tested secretory proteins from $P$. viticola, 62 suppressed elicitin-induced cell death (Liu et al. 2018). Seventy-eight of the 95 tested secretory proteins from Heterodera avenae suppressed BAX-induced cell death (Chen et al. 2018). For these biotrophic parasites, the possession of a large number of proteins that can suppress cell death might benefit propagation and colonization.

Among the 28 proteins that suppressed PBCN_002550-induced cell death (PBCN_003620, PBCN_005440, PBCN_008279, and PBCN_009251 could not suppress BAX-induced cell death), 18 proteins contained functional domains (Table 1). Some of these domains have been reported to be involved in pathogen infection, plant disease, and tolerance to biotic and abiotic stresses. PBCN 007081 contains a tyrosinase domain that can catalyze tyrosine to DOPA (Langfelder et al. 2003). L-DOPA reportedly reduces reaction oxygen species in soybean roots (Soares et al. 2011). An MYND zinc finger domain is found in PBCN_001987, and an RING-H2 zinc finger is found in PBCN_009214. Some proteins containing the RING-H2 zinc finger reportedly have functions in tolerance to abiotic stresses (Ko et al. 2006; Sahin-Cevik and Moore 2006; Zeng et al. 2014). PBCN_009251, PBCN_001204, PBCN_ 005456, PBCN_006649, PBCN_006697, and PBCN_009249 contain ankyrin repeats, which mediate protein-protein interactions in widely diverse families of proteins (Sedgwick and Smerdon 1999). Some ankyrin repeat-containing proteins from plants are involved in disease resistance, antioxidation metabolism, reactive oxygen production, and biotic and abiotic stresses (Böttner et al. 2009; Li et al. 2013; Sakamoto et al. 2008; Yan et al. 2002). In addition to the ankyrin repeat domain, a WD40 domain is found in PBCN_005456. Some proteins containing a WD40 domain are reportedly associated with plant tolerance to abiotic stresses and control the early stages of infection by Rhizobia in legumes (Kiss et al. 2009; Kong et al. 2015).

In conclusion, the functions of $P$. brassicae secretory proteins expressed during the primary infection stage in the induction and suppression of plant immunity were investigated. The results showed that only two secretory proteins induced plant immunity and that most of the secretory proteins suppressed plant immunity. These findings expanded our understanding of the functions of $P$. brassicae secretory proteins in interactions between $P$. brassicae and plants. Whether the effects of these secretory proteins in plant cell death are beneficial for $P$. brassicae infection and the mechanism through which these secretory proteins manipulate plant immunity remain unclear and are worth additional investigation/research. Future studies will focus on the targets of these secretory proteins and the functions and molecular mechanisms of these secretory proteins in $P$. brassicae infection.

\section{ACKNOWLEDGMENTS}

We thank Xiaodong Wang from Hebei Agricultural University for providing the pSUC2-Ps87 and pSUC2-Mg87 vectors.

\section{LITERATURE CITED}

Bai, S., Liu, J., Chang, C., Zhang, L., Maekawa, T., Wang, Q., Xiao, W., Liu, Y., Chai, J., Takken, F. L. W., Schulze-Lefert, P., and Shen, Q. 2012. Structure-function analysis of barley NLR immune receptor MLA10 reveals its cell compartment specific activity in cell death and disease resistance. PLoS Pathog 8:e1002752.

Block, A., Toruno, T. Y., Elowsky, C. G., Zhang, C., Steinbrenner, J., Beynon, J., and Alfano, J. R. 2014. The Pseudomonas syringae type III effector HopD1 suppresses effector-triggered immunity, localizes to the endoplasmic reticulum, and targets the Arabidopsis transcription factor NTL9. New Phytol. 201:1358-1370.

Böttner, S., Iven, T., Carsjens, C. S., and Droge-Laser, W. 2009. Nuclear accumulation of the ankyrin repeat protein ANK1 enhances the auxinmediated transcription accomplished by the bZIP transcription factors BZI1 and BZI-2. Plant J. 58:914-926.

Bulman, S., Richter, F., Marschollek, S., Benade, F., Julke, S., and Ludwig-Müller, J. 2019. Arabidopsis thaliana expressing PbBSMT, a gene encoding a SABATH-type methyltransferase from the plant pathogenic protist Plasmodiophora brassicae, show leaf chlorosis and altered host susceptibility. Plant Biol. :120-130.

Chai, A. L., Xie, X. W., Shi, Y. X., and Li, B. J. 2014. Research status of clubroot (Plasmodiophora brassicae) on cruciferous crops in China. Can. J. Plant Pathol. :142-153.

Chen, C., Chen, Y., Jian, H., Yang, D., Dai, Y., Pan, L., Shi, F., Yang, S., and Liu, Q. 2018. Large-scale identification and characterization of Heterodera avenae putative effectors suppressing or inducing cell death in Nicotiana benthamiana. Front. Plant Sci. 8:2062.

Chen, P., Wang, C., Soong, S., and To, K. 2003. Complete sequence of the binary vector pBI121 and its application in cloning T-DNA insertion from transgenic plants. Mol. Breed. 11:287-293.

Chen, S., Songkumarn, P., Venu, R. C., Gowda, M., Bellizzi, M., Hu, J., Liu, W., Ebbole, D., Meyers, B., Mitchell, T., and Wang, G. 2013. Identification and characterization of in planta-expressed secreted effector proteins from Magnaporthe oryzae that induce cell death in rice. Mol. Plant-Microbe Interact. 26:191-202.

Cheng, Z., Wei, Z., and Xu, Z. 1994a. PEG-mediated gene transfer into Brassica napus protoplasts and regeneration of transgenic plants. Acta Biol. Exp. Sin. 27:341-351.

Cheng, Z., Wei, Z., and Xu, Z. 1994b. Study on hypocotyl protoplast culture of rapeseed. Chin. J. Biotechnol. 10:30-34.

Dixon, G. R. 2009. The occurrence and economic impact of Plasmodiophora brassicae and clubroot disease. J. Plant Growth Regul. 28:194-202.

Erickson, J. L., Adlung, N., Lampe, C., Bonas, U., and Schattat, M. H. 2018. The Xanthomonas effector XopL uncovers the role of microtubules in stromule extension and dynamics in Nicotiana benthamiana. Plant J. 93:856-870.

Feng, J., Xiao, Q., Hwang, S. F., Strelkov, S. E., and Gossen, B. D. 2012. Infection of canola by secondary zoospores of Plasmodiophora brassicae produced on a nonhost. Eur. J. Plant Pathol. 132:309-315.

Groskreutz, D. J., Sherf, B. A., Wood, K. V., and Schenborn, E. T. 1995. Increased expression and convenience with the new pGL3 luciferase reporter vectors. Promega Notes 50:2-6.

Gu, B., Kale, S. D., Wang, Q., Wang, D., Pan, Q., Cao, H., Meng, Y., Kang, Z., Tyler, B. M., and Shan, W. 2011. Rust secreted protein Ps87 is conserved in diverse fungal pathogens and contains a RXLR-like motif sufficient for translocation into plant cells. PLoS One 6:e27217.

Hogenhout, S. A., Van der Hoorn, R. A. L., Terauchi, R., and Kamoun, S. 2009. Emerging concepts in effector biology of plant-associated organisms. Mol. Plant-Microbe Interact. 22:115-122.

Jacobs, K. A., Collins-Racie, L. A., Colbert, M., Duckett, M., Golden-Fleet, M., Kelleher, K., Kriz, R., LaVallie, E. R., Merberg, D., Spaulding, V., Stover, J., Williamson, M. J., and McCoy, J. M. 1997. A genetic selection for isolating cDNAs encoding secreted proteins. Gene 198:289-296.

Jones, J. D. G., and Dangl, J. L. 2006. The plant immune system. Nature 444: 323-329.

Kageyama, K., and Asano, T. 2009. Life cycle of Plasmodiophora brassicae. J. Plant Growth Regul. 28:203-211.

Kamoun, S., van West, P., Vleeshouwers, V. G., de Groot, K. E., and Govers, F. 1998. Resistance of Nicotiana benthamiana to Phytophthora infestans is mediated by the recognition of the elicitor protein INF1. Plant Cell 10:1413-1425.

King, S. R., McLellan, H., Boevink, P. C., Armstrong, M. R., Bukharova, T., Sukarta, O., Win, J., Kamoun, S., Birch, P. R., and Banfield, M. J. 2014. Phytophthora infestans RXLR effector PexRD2 interacts with host 
MAPKKK epsilon to suppress plant immune signaling. Plant Cell 26: 1345-1359.

Kiss, E., Olah, B., Kalo, P., Morales, M., Heckmann, A. B., Borbola, A., Lozsa, A., Kontar, K., Middleton, P., Downie, J. A., Oldroyd, G. E. D., and Endre, G. 2009. LIN, a novel type of U-Box/WD40 protein, controls early infection by Rhizobia in legumes. Plant Physiol. 151:1239-1249.

Ko, J., Yang, S. H., and Han, K. 2006. Upregulation of an Arabidopsis RING$\mathrm{H} 2$ gene, XERICO, confers drought tolerance through increased abscisic acid biosynthesis. Plant J. 47:343-355.

Kong, D., Li, M., Dong, Z., Ji, H., and Li, X. 2015. Identification of TaWD40D, a wheat WD40 repeat-containing protein that is associated with plant tolerance to abiotic stresses. Plant Cell Rep. 34:395-410.

Krijger, J. J., Horbach, R., Behr, M., Schweizer, P., Deising, H. B., and Wirsel, S. G. R. 2008. The yeast signal sequence trap identifies secreted proteins of the hemibiotrophic corn pathogen Colletotrichum graminicola. Mol. PlantMicrobe Interact. 21:1325-1336.

Krogh, A., Larsson, B., von Heijne, G., and Sonnhammer, E. L. L. 2001. Predicting transmembrane protein topology with a hidden Markov model: Application to complete genomes. J. Mol. Biol. 305:567-580.

Lacomme, C., and Cruz, S. S. 1999. Bax-induced cell death in tobacco is similar to the hypersensitive response. Proc. Natl. Acad. Sci. USA 96:7956-7961.

Langfelder, K., Streibel, M., Jahn, B., Haase, G., and Brakhage, A. A. 2003. Biosynthesis of fungal melanins and their importance for human pathogenic fungi. Fungal Genet. Biol. 38:143-158.

Li, D., Wang, F., Liu, B., Zhang, Y., Huang, L., Zhang, H., and Song, F. 2013. Ectopic expression of rice OSBIANK1, encoding an ankyrin repeatcontaining protein, in Arabidopsis confers enhanced disease resistance to Botrytis cinerea and Pseudomonas syringae. J. Phytopathol. 161:27-34.

Li, R., Li, Y., Kristiansen, K., and Wang, J. 2008. SOAP: Short oligonucleotide alignment program. Bioinformatics 24:713-714.

Li, X., Gao, C., Li, L., Liu, M., Yin, Z., Zhang, H., Zheng, X., Wang, P., and Zhang, Z. 2017. MoEnd3 regulates appressorium formation and virulence through mediating endocytosis in rice blast fungus Magnaporthe oryzae. PLoS Pathog 13:e1006449.

Lin, B., Zhuo, K., Chen, S., Hu, L., Sun, L., Wang, X., Zhang, L., and Liao, J. 2016. A novel nematode effector suppresses plant immunity by activating host reactive oxygen species-scavenging system. New Phytol. 209:1159-1173.

Liu, C., Pedersen, C., Schultz-Larsen, T., Aguilar, G. B., Madriz-Ordenana, K., Hovmoller, M. S., and Thordal-Christensen, H. 2016. The stripe rust fungal effector PEC6 suppresses pattern-triggered immunity in a host speciesindependent manner and interacts with adenosine kinases. New Phytol.

Liu, Y., Lan, X., Song, S., Yin, L., Dry, I. B., Qu, J., Xiang, J., and Lu, J. 2018. In planta functional analysis and subcellular localization of the oomycete pathogen Plasmopara viticola candidate RXLR effector repertoire. Front. Plant Sci. 9:286.

Ludwig-Müller, J., Julke, S., Geiss, K., Richter, F., Mithofer, A., Sola, I., Rusak, G., Keenan, S., and Bulman, S. 2015. A novel methyltransferase from the intracellular pathogen Plasmodiophora brassicae methylates salicylic acid. Mol. Plant Pathol. 16:349-364.

Luo, H., Chen, G., Liu, C., Huang, Y., and Xiao, C. 2014. An improved culture solution technique for Plasmodiophora brassicae infection and the dynamic infection in the root hair. Australas. Plant Pathol. 43:53-60.

Lyu, X., Shen, C., Fu, Y., Xie, J., Jiang, D., Li, G., and Cheng, J. 2016. A small secreted virulence-related protein is essential for the necrotrophic interactions of Sclerotinia sclerotiorum with its host plants. PLoS Pathog 12:e1005435.

Ma, Z., Zhu, L., Song, T., Wang, Y., Zhang, Q., Xia, Y., Qiu, M., Lin, Y., Li, H., Kong, L., Fang, Y., Ye, W., Wang, Y., Dong, S., Zheng, X., Tyler, B. M., and Wang, Y. 2017. A paralogous decoy protects Phytophthora sojae apoplastic effector PsXEG1 from a host inhibitor. Science 355:710-714.

McDonald, M. R., Sharma, K., Gossen, B. D., Deora, A., Feng, J., and Hwang, S. F. 2014. The role of primary and secondary infection in host response to Plasmodiophora brassicae. Phytopathol. 104:1078-1087.

Mittler, R., Herr, E. H., Orvar, B. L., van Camp, W., Willekens, H., Inze, D., and Ellis, B. E. 1999. Transgenic tobacco plants with reduced capability to detoxify reactive oxygen intermediates are hyperresponsive to pathogen infection. Proc. Natl. Acad. Sci. USA 96:14165-14170.

Nguyen, C. N., Perfus-Barbeoch, L., Quentin, M., Zhao, J., Magliano, M., Marteu, N., Da Rocha, M., Nottet, N., Abad, P., and Favery, B. 2018. A root-knot nematode small glycine and cysteine-rich secreted effector, MiSGCR1, is involved in plant parasitism. New Phytol. 217:687-699.

Pérez-López, E., Waldner, M., Hossain, M., Kusalik, A. J., Wei, Y., Bonham-Smith, P. C., and Todd, C. D. 2018. Identification of Plasmodiophora brassicae effectors: A challenging goal. Virulence 9:1344-1353.

Petersen, T. N., Brunak, S., von Heijne, G., and Nielsen, H. 2011. SignalP 4.0: Discriminating signal peptides from transmembrane regions. Nat. Methods 8:785-786.

Pitino, M., Armstrong, C. M., Cano, L. M., and Duan, Y. 2016. Transient expression of Candidatus Liberibacter Asiaticus effector induces cell death in Nicotiana benthamiana. Front. Plant Sci. 7:982.
Sahin-Cevik, M., and Moore, G. A. 2006. Isolation and characterization of a novel RING-H2 finger gene induced in response to cold and drought in the interfertile Citrus relative Poncirus trifoliata. Physiol. Plant. 126:153-161.

Sakamoto, H., Matsuda, O., and Iba, K. 2008. ITN1, a novel gene encoding an ankyrin-repeat protein that affects the ABA-mediated production of reactive oxygen species and is involved in salt-stress tolerance in Arabidopsis thaliana. Plant J. 56:411-422.

Schwelm, A., Badstober, J., Bulman, S., Desoignies, N., Etemadi, M., Falloon, R. E., Gachon, C. M. M., Legreve, A., Lukes, J., Merz, U., Nenarokova, A., Strittmatter, M., Sullivan, B. K., and Neuhauser, S. 2018. Not in your usual Top 10: Protists that infect plants and algae. Mol. Plant Pathol. 19: 1029-1044.

Schwelm, A., Dixelius, C., and Ludwig-Müller, J. 2016. New kid on the block the clubroot pathogen genome moves the plasmodiophorids into the genomic era. Eur. J. Plant Pathol. 145:531-542.

Schwelm, A., Fogelqvist, J., Knaust, A., Julke, S., Lilja, T., Bonilla-Rosso, G., Karlsson, M., Shevchenko, A., Dhandapani, V., Choi, S. R., Kim, H. G., Park, J. Y., Lim, Y. P., Ludwig-Müller, J., and Dixelius, C. 2015. The Plasmodiophora brassicae genome reveals insights in its life cycle and ancestry of chitin synthases. Sci. Rep. 5:11153.

Sedgwick, S. G., and Smerdon, S. J. 1999. The ankyrin repeat: A diversity of interactions on a common structural framework. Trends Biochem. Sci. 24: 311-316.

Sierra, R., Canas-Duarte, S. J., Burki, F., Schwelm, A., Fogelqvist, J., Dixelius, C., Gonzalez-Garcia, L. N., Gile, G. H., Slamovits, C. H., Klopp, C., Restrepo, S., Arzul, I., and Pawlowski, J. 2016. Evolutionary origins of Rhizarian parasites. Mol. Biol. Evol. 33:980-983.

Soares, A. R., Ferrarese, M. D. L., Siqueira-Soares, R. D., Marchiosi, R., Finger-Teixeira, A., and Ferrarese, O. 2011. The allelochemical L-DOPA increases melanin production and reduces reactive oxygen species in soybean roots. J. Chem. Ecol. 37:891-898.

Thordal-Christensen, H., Zhang, Z. G., Wei, Y. D., and Collinge, D. B. 1997. Subcellular localization of $\mathrm{H}_{2} \mathrm{O}_{2}$ in plants. $\mathrm{H}_{2} \mathrm{O}_{2}$ accumulation in papillae and hypersensitive response during the barley-powdery mildew interaction. Plant J. 11:1187-1194.

Wang, Q., Han, C., Ferreira, A., Yu, X., Ye, W., Tripathy, S., Kale, S. D., Gu, B., Sheng, Y., Sui, Y., Wang, X., Zhang, Z., Cheng, B., Dong, S., Shan, W., Zheng, X., Dou, D., Tyler, B. M., and Wang, Y. 2011. Transcriptional programming and functional interactions within the Phytophthora sojae RXLR Effector repertoire. Plant Cell 23:2064-2086.

Wei, Z., Laby, R. J., Zumoff, C. H., Bauer, D. W., He, S., Collmer, A., and Beer, S. V. 1992. Harpin, elicitor of the hypersensitive response produced by the plant pathogen Erwinia amylovora. Science 257:85-88.

Wojtaszek, P. 1997. Oxidative burst: An early plant response to pathogen infection. Biochem. J. 322:681-692.

Xiang, J., Li, X., Wu, J., Yin, L., Zhang, Y., and Lu, J. 2016. Studying the mechanism of Plasmopara viticola RxLR effectors on suppressing plant immunity. Front. Microbiol. 7:709.

Yan, J., Wang, J., and Zhang, H. 2002. An ankyrin repeat-containing protein plays a role in both disease resistance and antioxidation metabolism. Plant J. 29:193-202.

Yang, G., Tang, L., Gong, Y., Xie, J., Fu, Y., Jiang, D., Li, G., Collinge, D. B., Chen, W., and Cheng, J. 2018. A cerato-platanin protein SsCP1 targets plant PR1 and contributes to virulence of Sclerotinia sclerotiorum. New Phytol. 217:739-755.

Yeom, S. I., Baek, H. K., Oh, S. K., Kang, W. H., Lee, S. J., Lee, J. M., Seo, E., Rose, J. K. C., Kim, B. D., and Choi, D. 2011. Use of a secretion trap screen in pepper following Phytophthora capsici infection reveals novel functions of secreted plant proteins in modulating cell death. Mol. Plant-Microbe Interact. 24:671-684.

Yoshida, K., Saitoh, H., Fujisawa, S., Kanzaki, H., Matsumura, H., Yoshida, K., Tosa, Y., Chuma, I., Takano, Y., Win, J., Kamoun, S., and Terauchi, R. 2009. Association genetics reveals three novel avirulence genes from the rice blast fungal pathogen Magnaporthe oryzae. Plant Cell 21:1573-1591.

Yu, X., Tang, J., Wang, Q., Ye, W., Tao, K., Duan, S., Lu, C., Yang, X., Dong, S., Zheng, X., and Wang, Y. 2012. The RxLR effector Avh241 from Phytophthora sojae requires plasma membrane localization to induce plant cell death. New Phytol. 196:247-260.

Zeng, D., Hou, P., Xiao, F., and Liu, Y. 2014. Overexpressing a novel RING$\mathrm{H} 2$ finger protein gene, $O s R H P 1$, enhances drought and salt tolerance in rice (Oryza sativa L.). J. Plant Biol. 57:357-365.

Zhang, J., Wang, F., Liang, F., Zhang, Y., Ma, L., Wang, H., and Liu, D. 2018. Functional analysis of a pathogenesis-related thaumatin-like protein gene TaLr35PR5 from wheat induced by leaf rust fungus. BMC Plant Biol. 18:76.

Zheng, X., Wagener, N., McLellan, H., Boevink, P. C., Hua, C. L., Birch, P. R. J., and Brunner, F. 2018. Phytophthora infestans RXLR effector SFI5 requires association with calmodulin for PTI/MTI suppressing activity. New Phytol. 219:1433-1446. 